\title{
Using niche models of indicator species to predict the distribution of xerophytic shrub dune communities
}

\author{
R. M. Chefaoui ${ }^{1}$, S. Chozas ${ }^{2,3}$, O. Correia ${ }^{2}$, A. M. C. Santos ${ }^{2,3}$, and J. Hortal ${ }^{2,3}$ \\ ${ }^{1}$ CCMAR, Centro de Ciências do Mar, Universidade do Algarve, \\ Campus de Gambelas, Faro, 8005-139, Portugal \\ ${ }^{2}$ Centre for Ecology, Evolution and Environmental Changes, Lisbon, 1749-016, Portugal \\ ${ }^{3}$ National Museum of Natural History (MNCN-CSIC), Madrid, 28006, Spain
}

Correspondence to: R. M. Chefaoui (rosa.chef@gmail.com)

Received: 7 October 2015 - Revised: 27 January 2016 - Accepted: 2 February 2016 - Published: 9 February 2016

\begin{abstract}
Dune plant assemblages are affected by severe conditions, which makes them excellent models for studying the effects of species interactions and environmental conditions on community structure. We evaluate the relationship between the structure of dune communities, local environmental conditions and the suitability of climatic conditions for their characteristic species. Using data from an extensive survey of xerophytic inland sand dune scrub communities from Portugal - one of the most threatened habitat types of Europe - we identify the main gradients of vegetation composition, the different types of communities and their indicator shrub species. Then, we model the geographical responses of these species to the environment. Soil organic matter, isothermality and the habitat suitability for Stauracanthus genistoides defined the distribution of three shrub communities in the study area.
\end{abstract}

\section{Introduction}

Species distributions are affected by scenopoetic and biogeographical factors at large scales, with biotic interactions and community dynamics becoming more important at smaller scales (Soberón, 2007; Hortal et al., 2010). Xerophytic shrub communities growing on inland sand dunes constitute an excellent system for studying the scaling of the effects of species interactions, for they are subject to strong environmental filters and present diverse community compositions (Chozas et al., 2015). In an attempt to integrate the different processes affecting the distribution and co-occurrence of the shrub species inhabiting these habitats, we assessed whether the distribution of these communities can be predicted by the suitability of the environmental conditions for their indicator species.

\section{Methods}

We developed an extensive field survey of xerophytic shrub communities growing on inland dune habitats in southwest- ern Portugal. The composition and cover of shrub species was assessed in 115 plots $(10 \times 10 \mathrm{~m})$ randomly distributed within sandy soil areas with forest and semi-natural land use cover along a total extent of $1700 \mathrm{~km}^{2}$.

The most characteristic species of the xerophytic shrub communities previously described in the study area (Neto et al., 2002) were identified through the indicator value, using the indval function of "labdsv" package in R (Roberts, 2015).

We modelled the responses of these indicator species to environmental conditions (i.e. soil and climate) using occurrence records from the whole Iberian Peninsula. First, we used Ecological Niche Factor Analysis (ENFA; Hirzel et al., 2002) to model the climatic niche of each indicator species and determine the contribution of each environmental predictor to their marginality (i.e. the direction of maximum difference between the species niche and the conditions of the study area). Mahalanobis distance (MD; Clark et al., 1993) was used to identify the optimum for each species in the multivariate environmental space. Habitat suitability was calculated as the environmental distance to such an optimum and mapped to infer the potential distribution of the species. 
Table 1. Indicator species of each community. The indicator value (IndVal) is maximum when all individuals of a species occur in a single group and in all the sites of that group.

\begin{tabular}{llrr}
\hline Species & Community & IndVal & Probability \\
\hline Stauracanthus genistoides & S. genistoides & 0.6313 & 0.001 \\
Stauracanthus spectabilis & S. spectabilis & 0.9821 & 0.001 \\
Thymus camphoratus & S. spectabilis & 0.4065 & 0.002 \\
Ulex australis & U. australis & 0.7388 & 0.001 \\
\hline
\end{tabular}

Table 2. Marginality values for the climatic predictors used in the three keystone species analyses, according to an Ecological Niche Factor Analysis (ENFA). Most relevant variables (values beyond |0.4|) in bold.

\begin{tabular}{lrrr}
\hline Predictors & S. genistoides & S. spectabilis & U. australis \\
\hline $\begin{array}{l}\text { Annual mean } \\
\text { temperature }\end{array}$ & $\mathbf{0 . 5 1}$ & 0.37 & $\mathbf{0 . 5 6}$ \\
\hline $\begin{array}{l}\text { Annual } \\
\text { precipitation }\end{array}$ & 0.02 & -0.10 & -0.03 \\
\hline Isothermality & $\mathbf{0 . 4 9}$ & $\mathbf{0 . 7 1}$ & $\mathbf{0 . 5 2}$ \\
\hline $\begin{array}{l}\text { Mean monthly } \\
\text { solar radiation }\end{array}$ & 0.07 & 0.03 & 0.05 \\
\hline $\begin{array}{l}\text { Mean temperature } \\
\text { wettest quarter }\end{array}$ & 0.24 & 0.21 & 0.21 \\
\hline $\begin{array}{l}\text { Temperature } \\
\text { seasonality }\end{array}$ & $\mathbf{- 0 . 6 6}$ & $\mathbf{- 0 . 5 5}$ & $\mathbf{- 0 . 6 1}$ \\
\hline
\end{tabular}

The main gradients of vegetation composition were identified with a non-metric multidimensional scaling (NMS) ordination of the shrub cover data (Legendre and Legendre, 1998; McCune and Grace, 2002), using "vegan" package in $\mathrm{R}$ (Oksanen et al., 2015). The relationships between variations in community structure and the environmental variables were assessed with a vector fitting analysis. These variables include those that maximize the marginality of indicator species, soil organic matter content and aridity. The latter two were identified by Chozas et al. (2005) as the main factors acting on xerophytic shrub communities in a small region in the north of the study area. Both NMS and vector fitting were performed using "vegan" package in R.

\section{Results}

Four species were identified as indicators (Table 1). Three of them, Stauracanthus genistoides, Stauracanthus spectabilis and Ulex australis, are known to play keystone roles in their respective communities, so they were selected for the niche analyses. ENFA identified six significant predictors (Table 2), from which annual mean temperature, isothermality and temperature seasonality were able to explain most of the marginality of these species in the study area. All three species occur in localities with higher annual mean tempera-
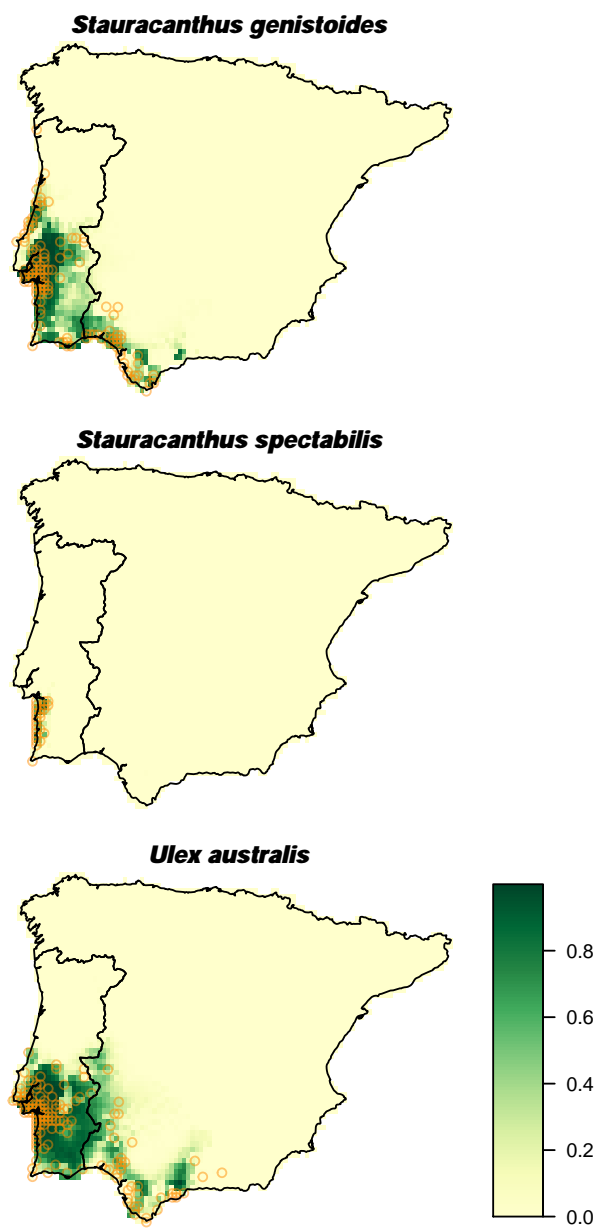

Figure 1. Habitat suitability maps for the three keystone indicator species, computed using Mahalanobis distance. Habitat suitability ranges from 0 (low suitability) to 1 (high suitability). Orange circles represent species occurrence data.

ture and isothermality, and lower seasonality of temperature than the rest of the Iberian Peninsula. According to MD analyses their suitable habitats are restricted to the southwestern quarter of the peninsula (Fig. 1).

NMS based on shrub cover and vector fitting between gradients of vegetation and environmental variables identified two main gradients in community structure: one defined by soil organic matter and another by habitat suitability of $S$. genistoides and isothermality (Fig. 2). These two gradients confirmed the occurrence of three types of shrub communities in the study area, dominated by either $S$. genistoides, $S$. spectabilis or $U$. australis, defining also an intermediate stage within the succession between $S$. genistoides and $U$. australis communities.

\section{Discussion}

Our results show a gradient between $S$. genistoides and $U$. australis communities for which soil organic matter is the 


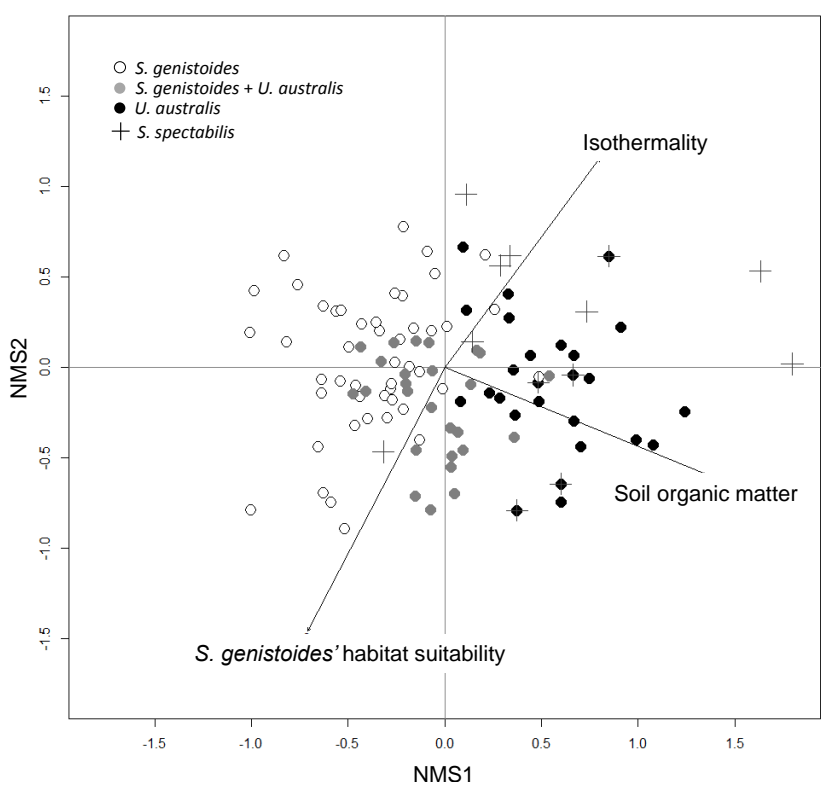

Figure 2. Non-metric multidimensional scaling ordination of study sites based on shrub cover. Dots and crosses represent study sites with the presence of the three main indicator species.

main driver throughout southern Portugal. These results coincide with those of Chozas et al. (2015) at a local scale, although at this regional scale this community gradient is also related to the habitat suitability for $S$. genistoides in several parts of the study area. ENFA revealed that the occurrence of the three keystone species of the xerophytic shrub communities is constrained by the same climatic factors in the Iberian Peninsula, restraining the distribution of the communities associated to them to the south-west. However, S. spectabilis shows a highly restricted potential distribution due to its high dependence of isothermal habitats (i.e. places with smaller daily variations in temperature). In contrast, $S$. genistoides and $U$. australis show much larger potential distribution, as well as a remarkably coincidence in their marginality. Given such similarities, the origin of the relationship between $S$. genistoides' habitat suitability and community structure remains elusive and may be related to geographical changes in the factors determining the dynamics of these communities. Therefore, further research is needed to determine whether there is a geographical coherence in the successional gradients between these communities, and whether there are regional differences in their responses to different environmental gradients.

Acknowledgements. We thank Adrián Escudero, Mariana Vale and one anonymous referee for their valuable comments on the manuscript. This study was funded by the Portuguese
FCT project COMDUNES (EXPL/BIA-BIC/2311/2013).

R. M. Chefaoui was supported by the FCT postdoctoral fellowship SFRH/BPD/85040/2012, S. Chozas by the FCT PhD grant $\mathrm{SFRH} / \mathrm{BD} / 65659 / 2009$, and afterwards by a FCT BI grant funded by the project COMDUNES (EXPL/BIA-BIC/2311/2013), A. M. C. Santos by a Marie Curie Intra-European Fellowship (IEF 331623 "COMMSTRUCT"), and J. Hortal by a Spanish DGCyT Ramón y Cajal grant.

Edited by: S. Navarrete

Reviewed by: A. Escudero, M. Vale, and one anonymous referee

\section{References}

Chozas, S., Correia, O., Porto, M., and Hortal, J.: Local and regional-scale factors drive xerophytic shrub community dynamics on Mediterranean stabilized dunes, Plant Soil, 391, 413-426, 2015.

Clark, J., Dunn, J., and Smith, K.: A multivariate model of female black bear habitat use for a geographic information system, J. Wildlife Manage., 57, 519-526, 1993.

Hirzel, A., Hausser, J., Chessel, D., and Perrin, N.: Ecological-niche factor analysis: how to compute habitat-suitability maps without absence data?, Ecology, 83, 2027-2036, 2002.

Hortal, J., Roura-Pascual, N., Sanders, N. J., and Rahbek, C.: Understanding (insect) species distributions across spatial scales, Ecography, 33, 51-53, 2010.

Legendre, P. and Legendre, L.: Numerical Ecology, Elsevier, Amsterdam, the Netherlands, 1998.

McCune, B. and Grace, J. B.: Analysis of Ecological Communities, M. S. Design, MjM Software Design, Gleneden Beach, Oregon, available at: http://www.pcord.com (last access: 4 February 2016), 2002.

Neto, C.: A flora e a vegetaçao do superdistrito Sadense (Portugal), Guineana, 8, 1-269, available at: http: //dialnet.unirioja.es/servlet/articulo?codigo $=499527 \&$ info $=$ resumen\&idioma=POR (last access: 4 February 2016), 2002.

Oksanen, J., Blanchet, F. G., Kindt, R., Legendre, P., Minchin, P. R., O’Hara, R. B., Simpson, G. L., Solymos, P., Henry, M., Stevens, H., and Wagner, H.: Vegan: Community Ecology Package, available at: http://CRAN.R-project.org/package=vegan (last access: 4 February 2016), 2015.

Roberts, D. W.: Package "labdsv". Ordination and Multivariate Analysis for Ecology, available at: https://cran.r-project.org/web/ packages/labdsv/labdsv.pdf (last access: 4 February 2016), 2015.

Soberón, J.: Grinnellian and Eltonian niches and geographic distributions of species, Ecol. Lett., 10, 1115-1123, 2007. 